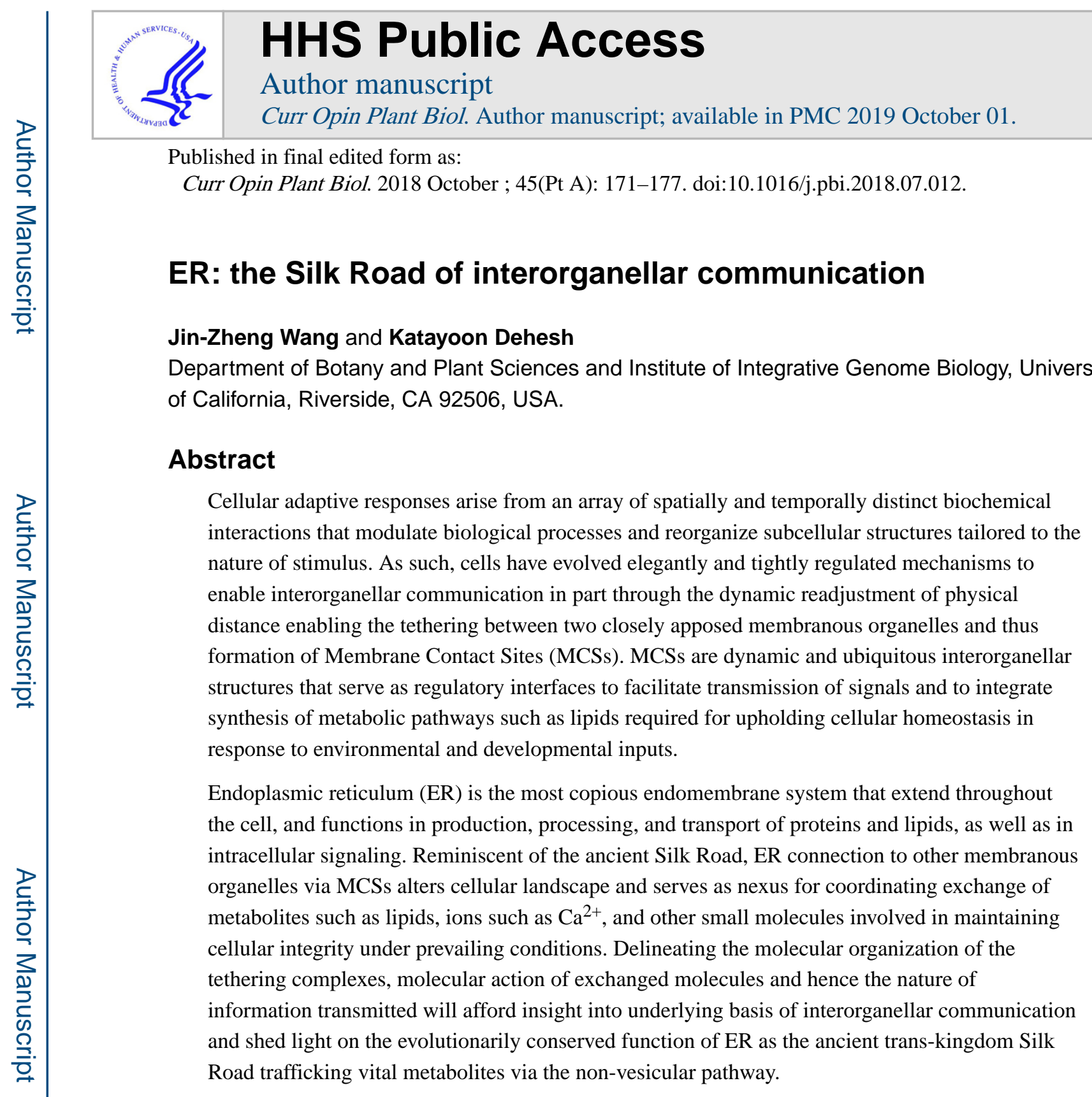

\title{
Introduction
}

The Tao initiates One, One deduces Two, Two give birth to Three, Three evolves the Universe. All things carry the Yin and embrace the Yang, living harmony by breathing together.

Correspondence to: Katayoon Dehesh.

Publisher's Disclaimer: This is a PDF file of an unedited manuscript that has been accepted for publication. As a service to our customers we are providing this early version of the manuscript. The manuscript will undergo copyediting, typesetting, and review of the resulting proof before it is published in its final citable form. Please note that during the production process errors may be discovered which could affect the content, and all legal disclaimers that apply to the journal pertain.

References and recommended reading

Papers of particular interest, published within the period of review, have been highlighted as:

- of special interest

•• of outstanding interest 
A defining characteristic of eukaryotic cells is the presence of intracellular membranes resulting in spatial separation of biological processes and by extension compartmentalization of metabolites in defined cellular compartments (organelles). Establishment of interorganellar communication, a profound consequence of emergence of eukaryotes, enabled coordinated scaling of biological processes required to meet metabolic and energy demands of the cell.

Endoplasmic reticulum (ER) is the most abundant endomembrane system that plays a key role in maintenance of cellular homeostasis in response to exogenous and endogenous inputs largely through interorganellar communication. The ER membranes are functionally connected to all membranes of the secretory and endocytic pathways via vesicular transport through physical fusion with vesicles [1,2]. However, contacts of the ER with other membranous organelles is through formation of Membrane Contact Sites (MCSs), a nonvesicular-pathway. The function of non-vesicular interorganellar communication pathway is through formation of direct associations between ER and other membrane compartments forming dynamic interfaces for trafficking of vital metabolites and information for timely adaptive responses $[3,4]$. An example is the proposed function of ER-PM contact sites in coordinating the interrelationship between sterols, sphingolipids, and phospholipids required for maintenance of PM composition and integrity[5].

MCSs are membrane micro-domains that can be formed between smooth tubular ER network with plasma membrane (PM), mitochondria, endosomes, peroxisomes, lipid droplets, Golgi, vacuoles and plastids [6-10]. It is of note that, the dense packing of membranous organelles within cell infers other potential frequent and random occurrence of transient encounters between organelles that differ from MCS formation. The differentiating hallmarks of MCSs as opposed to other member interactions are (a) tethering between two closely apposed intracellular membranes $(\sim 10-30 \mathrm{~nm})$; (b) the membranes might transiently hemi-fuse but do not fully fuse; (c) enrichment of selected proteins and/or lipids at the MCS, contributing to the formation of tethering complexes, or functioning as communication mediators; (d) formation of MCSs result in functional and/or compositional alteration of one of the two connected organelles[11]. Another key feature of MCSs is their dynamically varying abundance and remodeled structure depending on the interacting organelles, cell type, the functional state of the cell, and in response to developmental and external stimuli $[6,12,13]$.

This review focuses on some of the most recent findings of the nature of tethering complexes across kingdoms, between ER and mitochondria, plastids, and PM (Figure 1) and their respective roles in the exchange of lipids and the evolutionarily conserved signaling molecule, $\mathrm{Ca}^{2+}$, and to provide some perspectives for future studies. 


\section{Structural components of MCSs}

\section{ER-mitochondria}

Physical interaction between ER and mitochondria, commonly referred to as MitochondriaAssociated Membrane (MAM) [14], was first established by subcellular fractionation studies on rat liver using differential centrifugation [15] followed by direct visualization in living Hela cells using fluorescent proteins [16]. In yeast, MAM contact sites are formed by the ER-Mitochondria Encounter Structure (ERMES) tethering complex connecting the ER membrane to the mitochondrial outer membrane $[17,18]$. The core of ERMES complex is composed of four subunits: Mmm1 that is an ER transmembrane protein, Mdm34 and Mdm10 are proteins integral to mitochondrial outer membrane, and Mdm12 is the soluble cytosolic subunit (Figure 2A) [17].

Three of those four proteins (Mmm1, Mdm12 and Mdm34) contain a synaptotagmin-like mitochondrial-lipid binding protein (SMP) domain. Bioinformatics analysis using SMP domain identified PDZD8 as a structural and functional ortholog of the yeast Mmm1protein in mammalian ER membrane [19]. Thus far however, there are no reports on other ERMES orthologs.

In plants the direct connection between ER and mitochondria has been confirmed, but the molecular structure and function of these connections have remained elusive. Examination of the model plant Physcomitrella patens has provided visual evidence for the existence of mitochondria-ER interactions in plants and their correlation with mitochondrial constriction and fission [20]. The same group has reported that a protein of unknown function (mitochondria-ER-localized LEA-related LysM domain protein 1; MELL1) defines the abundance of mitochondrial association to the ER, and modulates mitochondrial shape and number. This suggests that MELL1 protein might be one of the components of ERMES in Physcomitrella patens (Figure 2B) [20]. The comparative analyses using full length protein sequences has not successfully identified potential ERMES candidates in plants [20]. However, a modified and targeted sequence analyses using SMP domain of ERMES complex, combined with quantitative proteomic of subcellular membrane recently employed for identification of mitochondrial outer membrane proteins [21], could be instrumental in identification of the tethering complex proteins connecting ER to mitochondria outer membrane in plants.

\section{ER-plastids}

Application of optical tweezers on ruptured Arabidopsis protoplast provided the first evidence for the physical association between ER and plastids [9]. These studies demonstrated that even at an applied force of $400 \mathrm{pN}$, ER fragments could not be detached from chloroplasts, a circumstantial evidence for protein-protein interactions at the ERchloroplast MCSs $[9,22]$. Subsequent transorganellar complementation studies demonstrated biochemical continuity of ER and chloroplasts and provided a clear evidence for functionality of ER-plastid MCSs [23]. These assays were based on mutating pathway activities in one organelle and testing of substrate accessibility by retargeting the functional enzymes to the companion organelle. This approach enabled complementation of plastidial 
vte1 mutant phenotype by the plastidial tocopherol cyclase retargeted to the ER, thus leading to the proposed hemifusion-based model for MCSs formation between ER and plastids [23]. The identity of tethering complex proteins of ER-plastids MCSs is still missing, however one of the lipase/acylhydrolases, BnCLIP1 localized at MCSs between ER and chloroplasts is viewed as a potential candidate [24].

Using living imaging implicated interactions between plastidial extensions known as stromules (stroma-filled tubules) and ER [25]. The study showed correlative dynamics between stromules and the cortical ER tubules, thereby suggesting that the interacting surfaces might serve as conduits for bidirectional metabolic exchanges between the two organelles [25]. In addition, extension of stromules along microtubules (MTs) and their connection to actin filaments as anchoring points surrounding nuclei led to the suggestion that stromules direct movement of chloroplasts to the nuclei during innate immunity [26]. ER surrounding of stromules suggests that formation of MCSs may stabilize stromules, similarly to anchoring function of actins [26,27]. This is line with the proposed role of cytoskeleton in stabilizing MCSs forming membranes, as the results of the connection of actin and microtubule to the ER-PM contact sites [28].

\section{ER-PM contact sites (EPCSs)}

The contact sites between ER and PM (EPCSs) facilitate communication between intracellular and extracellular compartments. The tethering complexes connecting the two membranes were revealed in yeast, mammals, and plants [1,29-34].

In yeast, three families of ER-PM tethering proteins were identified: Ist2 (related to mammalian TMEM16 ion channels), the tricalbins (Tcb1/2/3, orthologs of the extended synaptotagmins), and SUPPRESSOR OF CHOLINE SENSITIVITY2 (Scs2) and Scs22 (Figure 3A) [29,32]. Loss of these proteins not only dissociated ER from PM, but also misregulated phosphoinositide signaling at the PM, and constitutively activated the ER unfolded protein response. This is a clear indication of the critical role of EPCSs in a range of cellular activities including signaling, organelle morphology, and ER function [29,32].

The EPCSs in mammalian was first reported in the 1950s in muscle cell [33], subsequently recognized in neurons [34], and eventually observed in all cells, leading to recognition of the importance of cell type and the functional state of the cell in altering abundance and morphology of EPCSs [1]. In mammalians there are two types of tethers that, can and generally do coexist at the same contact sites. One is mediated by STIM1 and Orai and the other by E-Syts $[35,36]$. The latter is comprised of three E-Syts (E-Syt1, E-Syt2, and ESyt3). These proteins contain a membrane anchoring hairpin allowing biding to ER. This interaction is critically dependent on the presence of PI $(4,5) \mathrm{P}$ in the PM and is additionally regulated by elevation of cytosolic $\mathrm{Ca}^{2+}[35,36]$.

In plants, ER-PM anchor/contact is formed by three families of ER-PM tethering proteins namely (1) NET3C, member of a plant-specific superfamily (NET) of actin-binding protation [37], (2) Vesicle-Associated Protein 27 (VAP27), a plant homolog of the yeast Scs2 ER-PM tethering proteins [38], and (3) the actin and microtubule networks [28,39]. Moreover, a phospholipid binding Synaptotagmin1 (SYT1) was found to be a plant ortholog 
of the mammal extended synaptotagmins and yeast tricalbins families of ER-PM anchors [40]. The proposed function of SYT1 at ER-PM contact sites is supported by its colocalization with VAP27, a known ER-PM MCSs marker (Figure 3B) [40,41]. Functional identification of the trans-kingdom conserved SYT1 at ER-PM contact sites is an example of a MCS component coordinating cellular responses to environmental stresses [40].

\section{Cargos of MCSs}

\section{Lipid transport via MCSs}

The building block of bilayer cell membranes are phospholipids, but the compositional heterogeneity of membrane define their functional specificity, and as such lipid composition and intrinsic membrane proteins must be tightly regulated.

Cellular fatty acids (FAs) and lipid synthesis are compartmentalized biochemical processes. In photosynthetic eukaryotic cells, FAs are predominantly synthesized in chloroplasts, followed by their subsequent export to the ER for phospholipid and triacylglycerol synthesis [42]. Conversely, ER is the site of diacylglycerol synthesis, the substrate of galactolipids, the lipid species in the chloroplast membranes [42]. Hence FA and lipid trafficking between chloroplasts and the ER is essential for cellular survival.

In non-photosynthetic eukaryotic cells, the majority of membrane lipids are synthesized in the ER and then delivered to other membranes from which lipid metabolites are returned to the ER for metabolic recycling [43].

There are two major routes of lipid transport, one pathway of delivery by vesicular trafficking along the secretory and endocytic pathways, and the other is through MCSs. Interestingly, the delivery of membrane lipids from the ER to the PM occurs faster than the delivery of membrane and secretory proteins via vesicular traffic [44]. In addition, pharmacological and genetic manipulations that result in inhibition of vesicular transport do not block lipid delivery from the ER to the PM [44]. Moreover, hydrophobic nature of most membrane lipids and thus absence of spontaneous diffusion through the cytosol, provides evidence for non-vesicular lipid transport as in inevitable cooperation venue between the ER and mitochondria, and ER and plastids [45].

ER-mitochondria-Mitochondria are semiautonomous organelles whose replication is dependent on the delivery of essential building blocks such as lipids. Mitochondria require the delivery of phosphatidylserine (PS) and phosphatidic acid (PA) as substrates for an in house synthesis of phosphatidylethanolamine (PE), phosphatidylglycerol (PG), and cardiolipin (CL). In addition, mitochondria are unable to synthesize other necessary lipids such as phosphatidylcholine (PC), phosphatidylinositol (PI), sterols and sphingolipids. Thus, mitochondria require lipid delivery from the ER, but they are not connected to the secretory pathway, and as such dependent on MCSs mediated influx of lipids from the ER [13].

The Primary function of ERMES in yeast is to transport phospholipid between two organelles. In fact the preferential interaction of Mmm1-Mdm12 complex with PC suggest that they function as primary transporters of ER-derived PC to mitochondria [46]. Further 
structural and functional analysis of Mmm1-Mdm12 complex supports that ERMES is responsible for not only membrane tethering but also facilitating efficient lipid exchange, such as PE and PS, at ER-mitochondria contact sites in yeast [47]. However, despite the ancient nature of ERMES complex, its loss in animal lineage, suggests that other protein complexes have replaced its functions in metazoans.

In Arabidopsis thaliana, there is a large lipid-enriched complex, designated the mitochondrial transmembrane lipoprotein (MTL), containing proteins such as the TOM complex and AtMic60 [48]. It is reported that AtMic60 contributes to the export of PE from mitochondria and the import of galactoglycerolipids from plastids during phosphate starvation. Presence of Mic60 and the necessity of PE export from mitochondria in non-plant cells suggest possible involvement of Mic60 in lipid trafficking between ER-mitochondria as is the case in other organisms $[48,49]$.

ER-plastid-The initial synthesis of FAs occurs in plastids, but the compartmentalized nature of lipid synthesis necessitates lipid trafficking between organelles [22] that happens via MCSs. One protein candidate shown to be localized at the ER/ Plastid MCSs is a lipases designated as BnCLIP1 reported to regulate plastidial development [24]. In Arabidopsis, there are several chloroplast localized subfamilies of acylhydrolases, with suggested function in facilitating fatty acids or lipid transport between ER and chloroplast [50].

ER-PM-Lipid transfer proteins (LPTs) are proposed to function in the exchange of lipids between membranes, primarily at the MCSs. It is proposed that that LPTs function as physical tethers between the two membrane bilayers with their lipid transfer module mediating lipid exchange. Some LTPs that act at ER-PM contact sites are either directly bound to the ER via hydrophobic insertions into the bilayer, or indirectly via interactions of a so-called FFAT motif (two phenylalanines in an acidic tract) present in their sequence [51].

In yeast, the separation of the ER from the PM caused by the loss of all six tethering proteins resulted in elevated levels of phosphatidylinositol-4-phosphate (PtdIns4P) at the PM, in concert with induction of the ER unfolded protein response, indicating critical roles for ERPM contacts in lipid transfer and ER function [29].

\section{Calcium homeostasis via MCSs}

Calcium $\left(\mathrm{Ca}^{2+}\right)$ in addition to its structural role, also functions as a secondary messenger regulating the signaling cascades in an array of developmental processes and responses to environmental signals. Function of $\mathrm{Ca}^{2+}$ within cellular microdomains in maintaining intracellular $\mathrm{Ca}^{2+}$ homeostasis is well established [11,52,53].

ER-mitochondria-Mitochondrial function and survival is regulated by $\mathrm{Ca} 2+$ signals commonly transmitted at MCSs between the ER and mitochondria [54]. Additional evidence that $\mathrm{Ca}^{2+}$ transfer from the ER to mitochondria occurs at MCSs stemmed from studies on the channel that allows $\mathrm{Ca}^{2+}$ to move across the inner mitochondrial membrane, called the mitochondrial $\mathrm{Ca}^{2+}$ uniporter (MCU). Interestingly despite low $\mathrm{Ca}^{2+}$ affinity of this channel, the high local $\mathrm{Ca}^{2+}$ concentration at MCSs enables MCU to function [55]. Moreover, $\mathrm{Ca}^{2+}$ uptake into the matrix at the microdomains is performed by the mitochondrial calcium 
uniporter complex, first identified in mammals [56-58] and recently in plants [59]. In mammalian, ER localized PDZD8 is required for $\mathrm{Ca}^{2+}$ uptake by mitochondria after its release from ER [19]. Importantly, mitochondrial $\mathrm{Ca}^{2+}$ uptake shapes cytosolic $\mathrm{Ca}^{2+}$ dynamics [60]. The tight association between mitochondrial and cytoplasmic $\mathrm{Ca}^{2+}$ dynamics is also shown in plants by demonstrating the connection between mitochondrial $\mathrm{Ca}^{2+}$ accumulation and the intensity of the cytoplasmic $\mathrm{Ca}^{2+}[61]$.

ER-plastid-Similar to mitochondria, $\mathrm{Ca}^{2+}$ signaling in plastid regulates intra-organellar functions such as crucial aspect of photosynthesis, including assembly of photosystem II, the regulation of stromal enzymes and other processes such as import of nuclear encoded proteins and organellar division [62-64]. In addition plastids regulate intracellular $\mathrm{Ca}^{2+}$ by modulating cytosolic $\mathrm{Ca}^{2+}$ levels $[65,66]$. It is unclear how plastidial $\mathrm{Ca}^{2+}$ levels are maintained, however, identification of potential plastidial localized MCU [59] suggests ER localized tethering complexes might assist in plastidial $\mathrm{Ca}^{2+}$ uptake that is released from ER.

ER-PM-During various cellular activities, the low concentration of free $\mathrm{Ca}^{2+}$ in cytosol at resting state must be compensated. ER-PM contacts are critically implicated to rapidly replenish the cytosolic $\mathrm{Ca}^{2+}$ levels in all cells, followed by signal amplification and transduction resulting from refilling the intracellular $\mathrm{Ca}^{2+}$ store [1].

\section{Conclusions and perspectives}

In this review, we have discussed the known tethering complexes, and the function of MCSs in transmission of $\mathrm{Ca}^{2+}$ signals and exchange of lipids between ER and other membranous organelles. Indeed systematic examination of MCSs confirmed their role as interorganellar contact sites, now accordingly referred to as a constituent of "organelle interactome" $[67,68]$. It is of note that focus on lipids and $\mathrm{Ca}^{2+}$ as cargos stems from the ER-centric view of most reports on contact sites. This focus is simply because of ER special role in $\mathrm{Ca}^{2+}$ regulation, and ER function as a central hub in phospholipid biosynthesis necessitating it to communicate via MCSs with other organelles that require phospholipids. One could easily surmise that considering the abundance of detectable MCSs, and the multitude types of tethers and additional protein components so far identified, function of MCSs most likely extends to the transfer of molecules other than lipids and $\mathrm{Ca}^{2+}$ [67]. In addition to the full extent identity of cargos, open questions yet to be addressed are the identity of tethering protein complexes in yeast and mammalians, that are even more pronounced in plants. The inventory of proteins identified in yeast and mammalian cells could offer a discovery platform for identification of tethering complexes in plants. However regardless of species, dynamic nature of the tethering complexes between ER and other membranous organelles raises many questions, such as how some tethers occur constitutively in the absence of any acute stimulus, whereas formation of other tethers require a trigger; whether different tethers accumulate at the same or at different contact sites; and how are these tethers recruited to their respective site of action? Additional question arises concerning the energetics of transport, for example how a lipid is enriched in an acceptor membrane relative to a donor membrane. 
In general, much remains to be discovered about MCSs and their role in cell and organismal physiology. But the rapid progress in this area will define the central role of ER as the transkingdom Silk Road of non-vesicular transport pathway.

\section{Acknowledgements}

We apologize to all the investigators whose research could not be cited due to space limitations. This work was supported by National Science Foundation (NSF) IOS-1036491, NSF IOS-1352478, and National Institutes of Health (NIH) R01GM107311 to KD.

\section{References}

1. Saheki Y, De Camilli P: Endoplasmic Reticulum-Plasma Membrane Contact Sites. Annu Rev Biochem2017, 86:659-684. [PubMed: 28301744]

2. Goring DR, Di Sansebastiano GP: Protein and membrane trafficking routes in plants: conventional or unconventional? J Exp Bot 2017, 69:1-5. [PubMed: 29267941]

3. Cohen S, Valm AM, Lippincott-Schwartz J: Interacting organelles. Current Opinion in Cell Biology 2018, 53:84-91. [PubMed: 30006038]

4. Helle SC, Kanfer G, Kolar K, Lang A, Michel AH, Kornmann B: Organization and function of membrane contact sites. Biochim Biophys Acta 2013, 1833:2526-2541. [PubMed: 23380708]

5. Quon E, Sere YY, Chauhan N, Johansen J, Sullivan DP, Dittman JS, Rice WJ, Chan RB, Di Paolo G, Beh CT, et al.: Endoplasmic reticulum-plasma membrane contact sites integrate sterol and phospholipid regulation. PLoS Biol 2018, 16:e2003864. [PubMed: 29782498]

6. Wu Y, Whiteus C, Xu CS, Hayworth KJ, Weinberg RJ, Hess HF, De Camilli P: Contacts between the endoplasmic reticulum and other membranes in neurons. Proc. Natl. Acad. Sci. U. S. A. 2017, 114:E4859-E4867. [PubMed: 28559323]

7. Phillips MJ, Voeltz GK: Structure and function of ER membrane contact sites with other organelles. Nat. Rev. Mol. Cell Biol. 2016, 17:69-82. [PubMed: 26627931]

8. Andersson MX: Chloroplast Contact to the Endoplasmic Reticulum and Lipid Trafficking In Plastid Development in Leaves during Growth and Senescence. Edited by: Springer, Dordrecht; 2013:155167. Advances in Photosynthesis and Respiration

9. Andersson MX, Goksör M, Sandelius AS: Optical manipulation reveals strong attracting forces at membrane contact sites between endoplasmic reticulum and chloroplasts. J. Biol. Chem 2007, 282:1170-1174. [PubMed: 17077082]

10. Salvador-Gallego R, Hoyer MJ, Voeltz GK: SnapShot: Functions of Endoplasmic Reticulum Membrane Contact Sites. Cell 2017, 171:1224-1224.e1221. [PubMed: 29149609]

11. Prinz WA: Bridging the gap: membrane contact sites in signaling, metabolism, and organelle dynamics. J. Cell Biol. 2014, 205:759-769. [PubMed: 24958771]

12. Yang Z, Zhao X, Xu J, Shang W, Tong C: A novel fluorescent reporter detects plastic remodeling of mitochondria-ER contact sites. J. Cell Sci. 2018, 131.

13. Murley A, Nunnari J: The Emerging Network of Mitochondria-Organelle Contacts. Mol. Cell 2016, 61:648-653. [PubMed: 26942669]

14. Vance JE: MAM (mitochondria-associated membranes) in mammalian cells: lipids and beyond. Biochim. Biophys. Acta 2014, 1841:595-609. [PubMed: 24316057]

15. Vance JE: Phospholipid synthesis in a membrane fraction associated with mitochondria. J. Biol. Chem 1990, 265:7248-7256. [PubMed: 2332429]

16. Rizzuto R, Pinton P, Carrington W, Fay FS, Fogarty KE, Lifshitz LM, Tuft RA, Pozzan T: Close contacts with the endoplasmic reticulum as determinants of mitochondrial $\mathrm{Ca} 2+$ responses. Science 1998, 280:1763-1766. [PubMed: 9624056]

17. Kornmann B, Currie E, Collins SR, Schuldiner M, Nunnari J, Weissman JS, Walter P: An ERmitochondria tethering complex revealed by a synthetic biology screen. Science 2009, 325:477481. [PubMed: 19556461] 
18. Murley A, Lackner LL, Osman C, West M, Voeltz GK, Walter P, Nunnari J: ER-associated mitochondrial division links the distribution of mitochondria and mitochondrial DNA in yeast. Elife 2013, 2:e00422. [PubMed: 23682313]

19. Hirabayashi Y, Kwon S-K, Paek H, Pernice WM, Paul MA, Lee J, Erfani P, Raczkowski A, Petrey DS, Pon LA, et al.: ER-mitochondria tethering by PDZD8 regulates Ca2+ dynamics in mammalian neurons. Science 2017, 358:623-630. [PubMed: 29097544]

20. Mueller SJ, Reski R: Mitochondrial Dynamics and the ER: The Plant Perspective. Front Cell Dev Biol 2015, 3:78. [PubMed: 26779478]

21. Duncan O, Taylor NL, Carrie C, Eubel H, Kubiszewski-Jakubiak S, Zhang B, Narsai R, Millar AH, Whelan J: Multiple lines of evidence localize signaling, morphology, and lipid biosynthesis machinery to the mitochondrial outer membrane of Arabidopsis. Plant Physiol. 2011, 157:10931113. [PubMed: 21896887]

22. Block MA, Jouhet J: Lipid trafficking at endoplasmic reticulum-chloroplast membrane contact sites. Curr. Opin. Cell Biol 2015, 35:21-29. [PubMed: 25868077]

23. Mehrshahi P, Stefano G, Andaloro JM, Brandizzi F, Froehlich JE, DellaPenna D: Transorganellar complementation redefines the biochemical continuity of endoplasmic reticulum and chloroplasts. Proc. Natl. Acad. Sci. U. S. A 2013, 110:12126-12131. [PubMed: 23818635]

24. Tan X, Wang Q, Tian B, Zhang H, Lu D, Zhou J: A Brassica napus lipase locates at the membrane contact sites involved in chloroplast development. PLoS One 2011, 6:e26831. [PubMed: 22046373]

25. Schattat M, Barton K, Baudisch B, Klösgen RB, Mathur J: Plastid stromule branching coincides with contiguous endoplasmic reticulum dynamics. Plant Physiol. 2011, 155:1667-1677. [PubMed: 21273446]

26. Kumar AS, Park E, Nedo A, Alqarni A, Ren L, Hoban K, Modla S, McDonald JH, Kambhamettu C, Dinesh-Kumar SP, et al.: Stromule extension along microtubules coordinated with actinmediated anchoring guides perinuclear chloroplast movement during innate immunity. Elife 2018, 7.

27. Erickson JL, Adlung N, Lampe C, Bonas U, Schattat MH: The Xanthomonas effector XopL uncovers the role of microtubules in stromule extension and dynamics in Nicotiana benthamiana. Plant J. 2017.

28. Wang P, Hawkins TJ, Richardson C, Cummins I, Deeks MJ, Sparkes I, Hawes C, Hussey PJ: The plant cytoskeleton, NET3C, and VAP27 mediate the link between the plasma membrane and endoplasmic reticulum. Curr. Biol 2014, 24:1397-1405. [PubMed: 24909329]

29. Manford AG, Stefan CJ, Yuan HL, Macgurn JA, Emr SD: ER-to-plasma membrane tethering proteins regulate cell signaling and ER morphology. Dev. Cell 2012, 23:1129-1140. [PubMed: 23237950]

30. Bayer EM, Sparkes I, Vanneste S, Rosado A: From shaping organelles to signalling platforms: the emerging functions of plant ER-PM contact sites. Curr. Opin. Plant Biol 2017, 40:89-96. [PubMed: 28865976]

31. Wang P, Hawes C, Hussey PJ: Plant Endoplasmic Reticulum-Plasma Membrane Contact Sites. Trends Plant Sci. 2017, 22:289-297. [PubMed: 27955928]

32. Omnus DJ, Manford AG, Bader JM, Emr SD, Stefan CJ: Phosphoinositide kinase signaling controls ERPM cross-talk. Mol Biol Cell 2016, 27:1170-1180. [PubMed: 26864629]

33. Porter KR, Palade GE: Studies on the endoplasmic reticulum. III. Its form and distribution in striated muscle cells. J Biophys Biochem Cytol 1957, 3:269-300. [PubMed: 13438910]

34. Rosenbluth J: Subsurface Cisterns and Their Relationship to Neuronal Plasma Membrane. Journal of Cell Biology 1962, 13:405-\&. [PubMed: 14493991]

35. Giordano F, Saheki Y, Idevall-Hagren O, Colombo SF, Pirruccello M, Milosevic I, Gracheva EO, Bagriantsev SN, Borgese N, De Camilli P: PI(4,5)P(2)-dependent and Ca(2+)-regulated ER-PM interactions mediated by the extended synaptotagmins. Cell 2013, 153:1494-1509. [PubMed: 23791178]

36. Idevall-Hagren O, Lu A, Xie BC, De Camilli P: Triggered Ca2+ influx is required for extended synaptotagmin 1-induced ER-plasma membrane tethering. Embo Journal 2015, 34:2291-2305. [PubMed: 26202220] 
37. Deeks MJ, Calcutt JR, Ingle EK, Hawkins TJ, Chapman S, Richardson AC, Mentlak DA, Dixon MR, Cartwright F, Smertenko AP, et al.: A superfamily of actin-binding proteins at the actinmembrane nexus of higher plants. Current Biology 2012, 22:1595-1600. [PubMed: 22840520]

38. Stefan CJ, Manford AG, Baird D, Yamada-Hanff J, Mao Y, Emr SD: Osh proteins regulate phosphoinositide metabolism at ER-plasma membrane contact sites. Cell 2011, 144:389-401. [PubMed: 21295699]

39. Wang P, Richardson C, Hawkins TJ, Sparkes I, Hawes C, Hussey PJ: Plant VAP27 proteins: domain characterization, intracellular localization and role in plant development. New Phytol. 2016, 210:1311-1326. [PubMed: 27159525]

40. Perez-Sancho J, Vanneste S, Lee E, McFarlane HE, del Valle AE, Valpuesta V, Friml J, Botella MA, Rosado A: The Arabidopsis Synaptotagmin1 Is Enriched in Endoplasmic Reticulum-Plasma Membrane Contact Sites and Confers Cellular Resistance to Mechanical Stresses. Plant Physiol 2015, 168:132-U837. [PubMed: 25792253]

41. Perez-Sancho J, Tilsner J, Samuels AL, Botella MA, Bayer EM, Rosado A: Stitching Organelles: Organization and Function of Specialized Membrane Contact Sites in Plants. Trends Cell Biol 2016, 26:705-717. [PubMed: 27318776]

42. Ohlrogge J, Browse J: Lipid biosynthesis. Plant Cell 1995, 7:957-970. [PubMed: 7640528]

43. van Meer G, Voelker DR, Feigenson GW: Membrane lipids: where they are and how they behave. Nature Reviews Molecular Cell Biology 2008, 9:112-124. [PubMed: 18216768]

44. Baumann NA, Sullivan DP, Ohvo-Rekila H, Simonot C, Pottekat A, Klaassen Z, Beh CT, Menon AK: Transport of newly synthesized sterol to the sterol-enriched plasma membrane occurs via nonvesicular equilibration. Biochemistry 2005, 44:5816-5826. [PubMed: 15823040]

45. Wang Z, Benning C: Chloroplast lipid synthesis and lipid trafficking through ER-plastid membrane contact sites. Biochem. Soc. Trans 2012, 40:457-463. [PubMed: 22435830]

46. AhYoung AP, Jiang J, Zhang J, Khoi Dang X, Loo JA, Zhou ZH, Egea PF: Conserved SMP domains of the ERMES complex bind phospholipids and mediate tether assembly. Proc Natl Acad Sci U S A 2015, 112:E3179-3188. [PubMed: 26056272]

47. Kawano S, Tamura Y, Kojima R, Bala S, Asai E, Michel AH, Kornmann B, Riezman I, Riezman H, Sakae Y, et al.: Structure-function insights into direct lipid transfer between membranes by Mmm1-Mdm12 of ERMES. Journal of Cell Biology 2018, 217:959-974. [PubMed: 29279306]

48. Li-Beisson Y, Neunzig J, Lee Y, Philippar K: Plant membrane-protein mediated intracellular traffic of fatty acids and acyl lipids. Curr. Opin. Plant Biol. 2017, 40:138-146. [PubMed: 28985576]

49. Michaud M, Gros V, Tardif M, Brugiere S, Ferro M, Prinz WA, Toulmay A, Mathur J, Wozny M, Falconet D, et al.: AtMic60 Is Involved in Plant Mitochondria Lipid Trafficking and Is Part of a Large Complex. Current Biology 2016, 26:627-639. [PubMed: 26898467]

50. Seo YS, Kim EY, Kim JH, Kim WT: Enzymatic characterization of class I DAD1-like acylhydrolase members targeted to chloroplast in Arabidopsis. FEBS Lett 2009, 583:2301-2307. [PubMed: 19527719]

51. Murphy SE, Levine TP: VAP, a Versatile Access Point for the Endoplasmic Reticulum: Review and analysis of FFAT-like motifs in the VAPome. Biochim Biophys Acta 2016, 1861:952-961. [PubMed: 26898182]

52. Himschoot E, Pleskot R, Van Damme D, Vanneste S: The ins and outs of Ca2+ in plant endomembrane trafficking. Curr. Opin. Plant Biol 2017, 40:131-137. [PubMed: 28965016]

53. Carrasco S, Meyer T: STIM Proteins and the Endoplasmic Reticulum-Plasma Membrane Junctions. Annual Review of Biochemistry, Vol 80 2011, 80:973-1000.

54. Csordas G, Renken C, Varnai P, Walter L, Weaver D, Buttle KF, Balla T, Mannella CA, Hajnoczky G: Structural and functional features and significance of the physical linkage between ER and mitochondria. J Cell Biol 2006, 174:915-921. [PubMed: 16982799]

55. Csordás G, Várnai P, Golenár T, Roy S, Purkins G, Schneider TG, Balla T, Hajnóczky G: Imaging interorganelle contacts and local calcium dynamics at the ER-mitochondrial interface. Mol. Cell 2010, 39:121-132. [PubMed: 20603080]

56. Baughman JM, Perocchi F, Girgis HS, Plovanich M, Belcher-Timme CA, Sancak Y, Bao XR, Strittmatter L, Goldberger O, Bogorad RL, et al.: Integrative genomics identifies MCU as an 
essential component of the mitochondrial calcium uniporter. Nature 2011, 476:341-345. [PubMed: 21685886]

57. De Stefani D, Raffaello A, Teardo E, Szabò I, Rizzuto R: A forty-kilodalton protein of the inner membrane is the mitochondrial calcium uniporter. Nature 2011, 476:336-340. [PubMed: 21685888]

58. Perocchi F, Gohil VM, Girgis HS, Bao XR, McCombs JE, Palmer AE, Mootha VK: MICU1 encodes a mitochondrial EF hand protein required for $\mathrm{Ca}(2+)$ uptake. Nature 2010, 467:291-296. [PubMed: 20693986]

59. Teardo E, Carraretto L, Wagner S, Formentin E, Behera S, De Bortoli S, Larosa V, Fuchs P, Lo Schiavo F, Raffaello A, et al.: Physiological Characterization of a Plant Mitochondrial Calcium Uniporter in Vitro and in Vivo. Plant Physiol. 2017, 173:1355-1370. [PubMed: 28031475]

60. Rizzuto R, De Stefani D, Raffaello A, Mammucari C: Mitochondria as sensors and regulators of calcium signalling. Nat. Rev. Mol. Cell Biol 2012, 13:566-578. [PubMed: 22850819]

61. Loro G, Drago I, Pozzan T, Schiavo FL, Zottini M, Costa A: Targeting of Cameleons to various subcellular compartments reveals a strict cytoplasmic/mitochondrial $\mathrm{Ca} 2+$ handling relationship in plant cells. Plant J. 2012, 71:1-13. [PubMed: 22372377]

62. Nomura H, Shiina T: Calcium signaling in plant endosymbiotic organelles: mechanism and role in physiology. Mol. Plant 2014, 7:1094-1104. [PubMed: 24574521]

63. Stael S, Wurzinger B, Mair A, Mehlmer N, Vothknecht UC, Teige M: Plant organellar calcium signalling: an emerging field. J. Exp. Bot 2012, 63:1525-1542. [PubMed: 22200666]

64. Carraretto L, Teardo E, Checchetto V, Finazzi G, Uozumi N, Szabo I: Ion Channels in Plant Bioenergetic Organelles, Chloroplasts and Mitochondria: From Molecular Identification to Function. Mol. Plant 2016, 9:371-395. [PubMed: 26751960]

65. Nomura H, Komori T, Kobori M, Nakahira Y, Shiina T: Evidence for chloroplast control of external Ca2+-induced cytosolic Ca2+ transients and stomatal closure. Plant J 2008, 53:988-998. [PubMed: 18088326]

66. Weinl S, Held K, Schlucking K, Steinhorst L, Kuhlgert S, Hippler M, Kudla J: A plastid protein crucial for Ca2+-regulated stomatal responses. New Phytol 2008, 179:675-686. [PubMed: 18507772]

67. Shai N, Yifrach E, van Roermund CWT, Cohen N, Bibi C, L IJ, Cavellini L, Meurisse J, Schuster R, Zada L, et al.: Systematic mapping of contact sites reveals tethers and a function for the peroxisomemitochondria contact. Nat Commun 2018, 9:1761. [PubMed: 29720625]

68. Valm AM, Cohen S, Legant WR, Melunis J, Hershberg U, Wait E, Cohen AR, Davidson MW, Betzig E, Lippincott-Schwartz J: Applying systems-level spectral imaging and analysis to reveal the organelle interactome. Nature 2017, 546:162-167. [PubMed: 28538724] 


\section{Highlights}

- Membrane Contact Sites (MCS) as interfaces for interorganellar communication

- MCSs enable differential intracellular lipid distribution

- MCSs facilitate $\mathrm{Ca}^{2+}$ homeostasis, a conserved signalling agent 


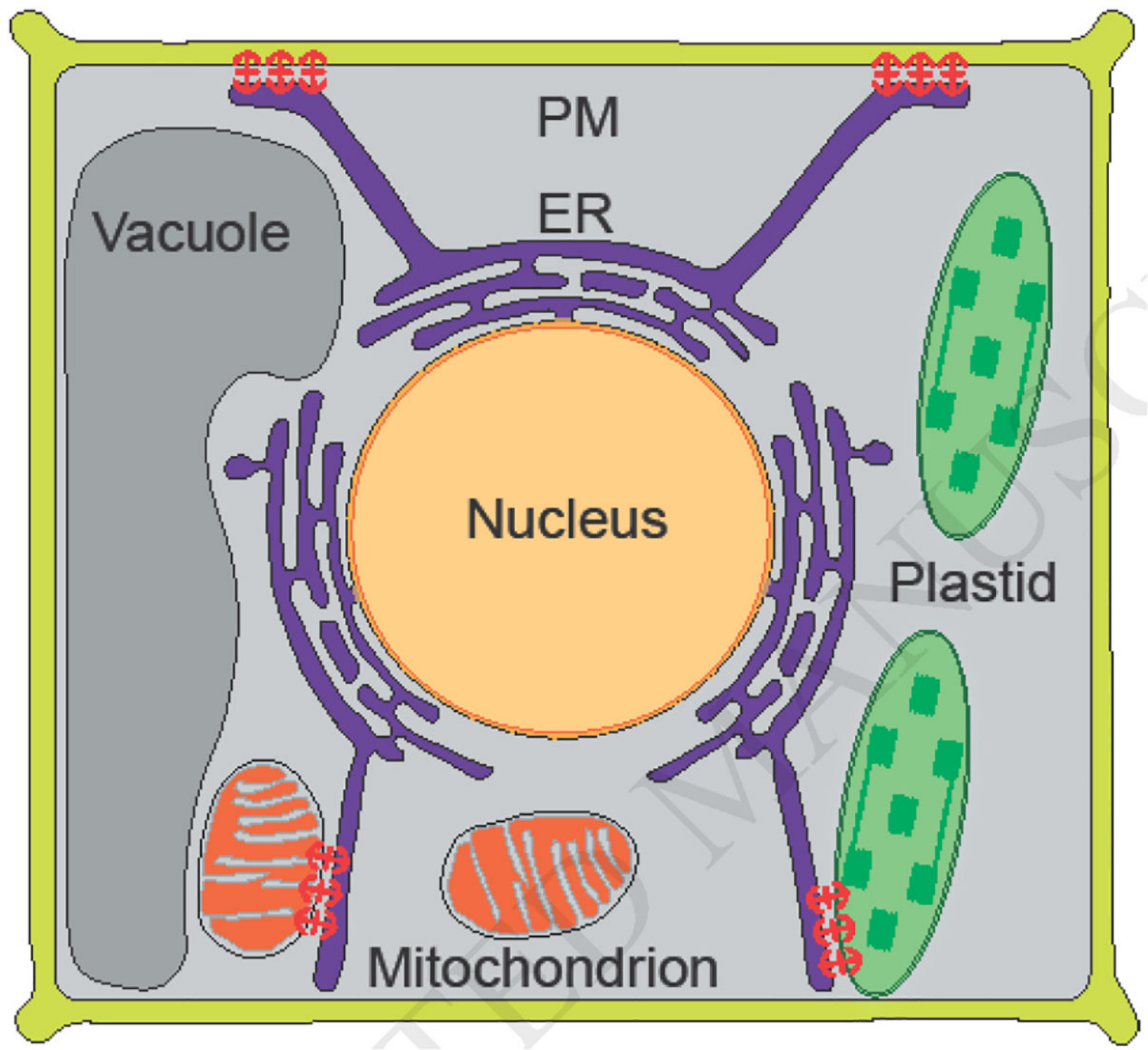

Figure 1.

Schematic presentation of the Silk Road of interorganellar communication, ER dynamically connecting with plasma membrane (PM), plastid and mitochondrion via membrane contact sites shown by anchors (red). 
A

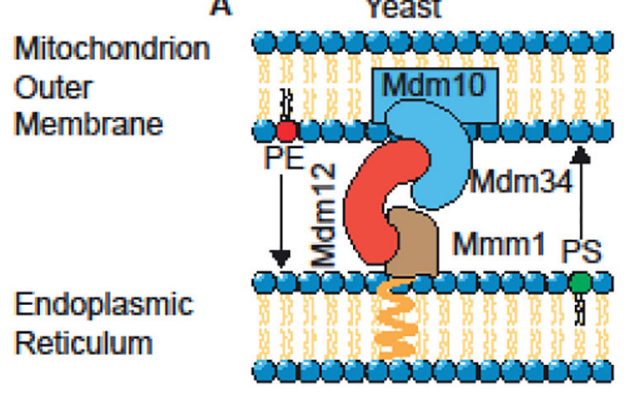

B Plant
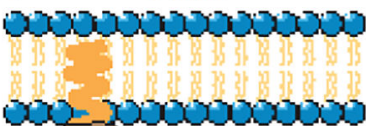

MELL1?

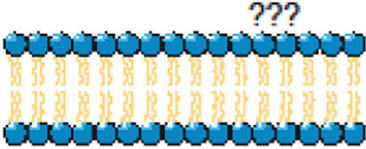

Figure 2.

Schematic model depicting known representatives of tethering complex proteins (Mmm1, Mdm32, Mdm34 and Mdm10 in yeast, and MELL1 in plant) and the lipids that can be exchanged at the ER-mitochondrion contact sites. 

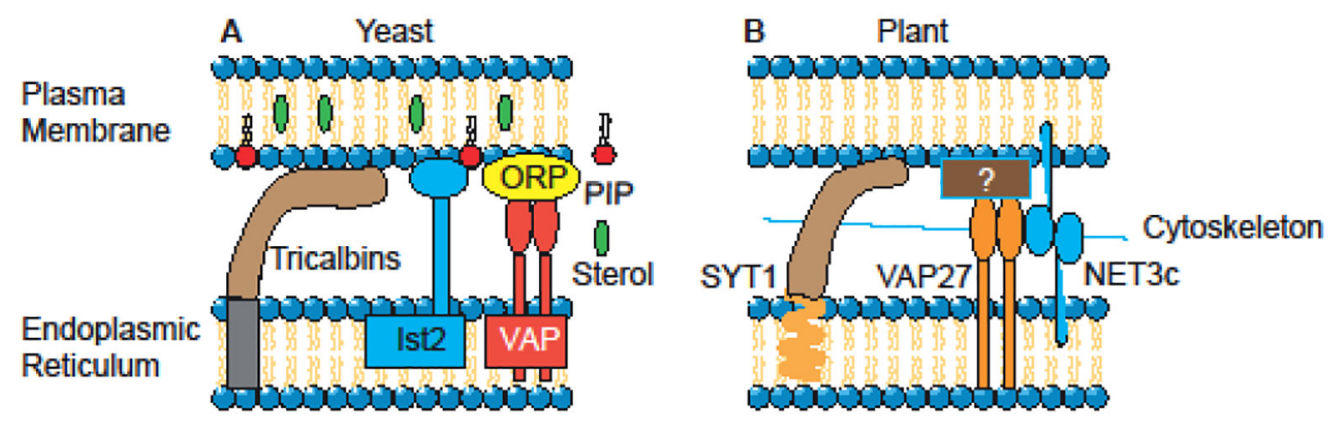

Figure 3.

Schematic model depicting known representatives of tethering complex proteins (tricalbins, Ist2 and VAP in yeast, and SYT1, VAP27 and NET3C in plant) and cytoskeleton at the ERPM contact sites. 